\title{
Bulky cutaneous metastasis from lung cancer
}

\section{Giuseppe Famularo', Alessandro Stasolla ${ }^{2}$}

\author{
${ }^{1}$ Internal Medicine, San Camillo Hospital, Rome, Italy, ${ }^{2}$ Radiology, San Camillo Hospital, Rome, Italy \\ Corresponding author: Dr. Giuseppe Famularo, E-mail: g.famularo@icloud.com
}

Sir,

A 65-year-old woman presented with a fungating tumor of her right arm that appeared three weeks prior and was rapidly enlarging. Her past history was unremarkable, she took no medications including over-the-counter medications before the illness, had no known allergies, and did not drink alcohol or use illicit drugs.

Examination revealed an alert, afebrile, normotensive woman. She appeared mildly ill. A bulky, fixed, ulcerated, slightly friable, and easily bleeding mass with a size of $12 \mathrm{~cm}$ in diameter and $8 \mathrm{~cm}$ in height in its greatest dimension was seen over the lateral surface of her right arm (Figs. la and lb). The patient fully moved the arm and did not complain of pain or reduced strength. Inspiratory crackles were present in both lungs, there was no asymmetry on neurologic strength testing and the remainder of the examination was normal. Laboratory test results were normal except for mild anemia (Hb $10.5 \mathrm{~g} /$ dl) and elevated C-reactive protein $(11.3 \mathrm{mg} / \mathrm{dl})$. A total-body computed tomography performed with the administration of contrast material disclosed a cancer of the right lung with brain and liver metastases and raised concern that the mass represented a metastasis to the skin. A biopsy of the skin lesion revealed a poorly differentiated squamous-cell carcinoma. The patient was discharged to a hospice facility and died one month later.

Autopsy series have detected metastases to soft tissues, including skeletal muscle, subcutaneous tissue and skin, in up to $9 \%$ of patients who died from metastatic lung carcinoma [1]. Lung cancer and malignancies of kidney, colon, breat and ovary are most commonly associated with metastases to the skin and other soft tissues [1,2]. Approximately

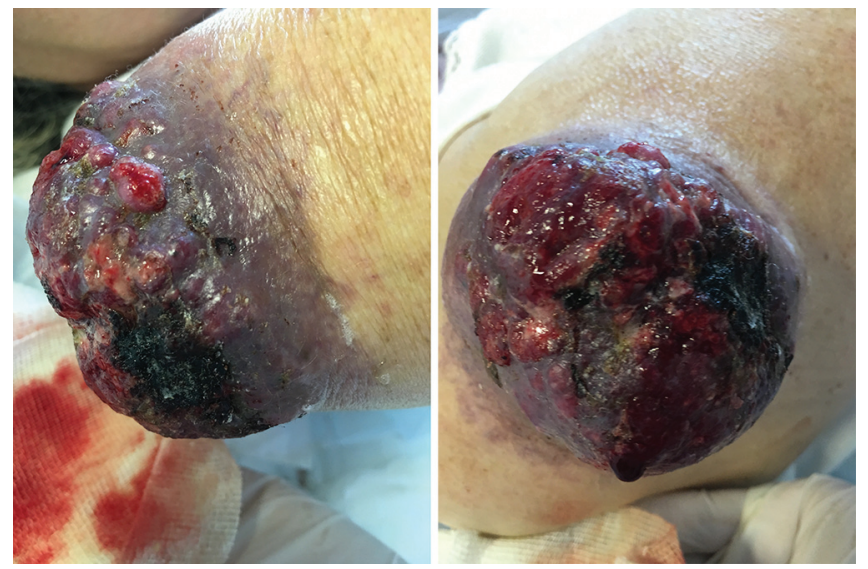

Figure 1: The patient had a bulky, fixed, ulcerated, slightly friable, and easily bleeding mass over the lateral surface of her right arm.

10 percent of patients with lung cancer develop metastases to the skin at any point in the course of the disease with a mean time of 6 months after the initial diagnosis [2,3]. Cutaneous metastases appear before or synchronously with the diagnosis of the primary tumor in about half of cases [3]. In our patient this was the first manifestation of an otherwise occult and advanced lung cancer. Lung cancer often presents in unusual ways but this is a very uncommon presentation.

All histological types of lung cancer may metastasize to the skin. Adenocarcinoma and squamous-cell carcinoma are more often implicated than other types and largecell carcinoma is the less represented type [3]. A wide morphologic spectrum of clinical appearances has been described in cutaneous metastases from lung cancer. This variable morphology includes, papules, plaques and ulcers with sizes ranging from $2 \mathrm{~mm}$ to 6 or more $\mathrm{cm}$ in diameter that can be single or multiple in the same site. The nodules may be mobile or fixed and hard or flexible with color ranging from flesh-colored to red, pink, purple, or

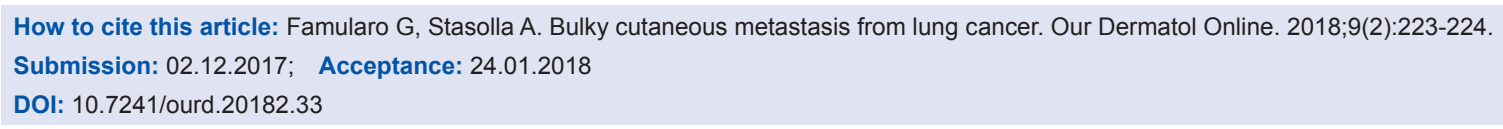


bluish black. The chest, abdomen, head and neck are most commonly involved [3]. Alopecia could be seen if the scalp or a burn scar is involved [4]. Cutaneous lymphangitis carcinomatosa could mimick a skin infection presenting as an eresypela-like or an eczematiform itchy rash due to invasion of the lymphatic vessels or from seeding after a surgical procedure [5]. This variable appearance could explain the failure in recognizing metastases to the skin at their first presentation as well as the delay in diagnosing the primary malignancy.

Bleeding may occur and it could be severe when masses are greater than $5 \mathrm{~cm}$. Patients rarely complain of pain at the site of the metastasis, however severely painful zosteriform lesions could result from penetration of the dorsal root ganglions [6].

Why tumors in the upper lobes of lungs have a greater probability to metastasize to the skin than tumors of the middle and lower lobes is unclear [7]. No other features of the primary tumor have been associated with an increased probability of metastasizing to the skin.

Surgery alone or combined with chemotherapy and/or radiation is the mainstay of treatment of patients with cutaneous metastases from lung cancer. However, most of them have end-stage disease with a poor outcome and high rates of short-term mortality.

\section{REFERENCES}

1. Perisano C, Spinelli MS, Graci C, Scaramuzzo L, Marzetti E, Barone C,et al. Soft tissue metastases in lung cancer: a review of the literature. Eur Rev Med Pharmacol Sci. 2012;16:1908-14.

2. Alcaraz I, Cerroni L, Rütten A, Kutzner H, Requena L. Cutaneous metastases from internal malignancies: a clinicopathologic and immunohistochemical review. Am J Dermatopathol. 2012;34:347-93.

3. Mollet TW, Garcia CA, Koester G. Skin metastases from lung cancer. Dermatol Online J. 2009;15:1.

4. Dreizen S, Dhingra H, Chiuten D, Umsawasdi T, Valdivieso M. Cutaneous and subcutaneous metastases of lung cancer. Postgrad Med. 1986; 80:111-6.

5. Prat L, Chouaid C, Kettaneh A, Fardet L. Cutaneous lymphangitis carcinomatosa in a patient with lung adenocarcinoma: case report and literature review. Lung Cancer. 2013;79:91-3.

6. Kikuchi Y, Matsuyama A, Nomura K. Zosteriform metastatic skin cancer: report of three cases and review of the literature. Dermatology. 2001;202:336-8.

7. Molina Garrido MJ, Guillén Ponce C, Soto Martínez JL, Martínez Y Sevila C, Carrato Mena A. Cutaneous metastases of lung cancer. Clin Transl Oncol. 2006; 8:330-3.

Copyright by Giuseppe Famularo, et al. This is an open access article distributed under the terms of the Creative Commons Attribution License, which permits unrestricted use, distribution, and reproduction in any medium, provided the original author and source are credited.

Source of Support: Nil, Conflict of Interest: None declared. 